\title{
Ángeles vestidos de obrero; Arte que no calla. (¡Como para inventarlo de nuevo!) ICTUS, TIT: El discurso teatral bajo la dictadura militar.
}

\author{
Angels in Labor; Art that won't be quiet. \\ (; to be reinvented, once again!) \\ ICTUS, TIT: Theatrical discourse in military dictatorship
}

Lorena Elízabeth Salas Ortíz

Universidad de Chile

lorenasalasortiz@yahoo.es

\begin{abstract}
SÍNTESIS
Este artículo propone un análisis de las obras Pedro, Juan y Diego, Tres Marías y Una Rosa y Lindo país esquina con vista al mar, de ICTUS, TIT y David Benavente, puestas en escena durante los años 1976 y 1979. A través de estas obras, el arte teatral es presentado como un ejercicio catártico y de memoria que reconstituye y transfiere la expresión del pueblo chileno, abatido por la violencia instaurada en la dictadura desde 1973 a 1990. El presente estudio reflexiona en torno al modo en que estos discursos se articulan a partir de la disidencia, como un arma política que regenera identidades silenciadas, creando nuevas posibilidades expresivas. Representaciones dentro de la representación, junto a nuevos sentidos surgidos de lineas aparentemente inconexas, elevan la voz de un pueblo y un arte que ha sido violentamente cercenado.
\end{abstract}

\section{ABSTRACT}

This paper analyses Pedro, Juan y Diego, Tres Marias y Una Rosa y Lindo país esquina con vista al mar, plays written by ICTUS, TIT and David Benavente, first staged during the years 1976 and 1979. Through these works, the Art of Theater is presented as a cathartic exercise that reconstitutes memory and transfers the expression of the Chilean people, deeply hurt by the violent dictatorship that took place from 1973 to 1990. This study reflects on the way these speeches are articulated from the dissident wing as a political weapon that regenerates silenced identities. It creates new expressive possibilities. In this, representations within the representation, 
along with new meanings emerged from seemingly unrelated lines, raise the voice of a people and an art that has been violently maimed.

Palabras clave: Teatro, memoria, identidad, análisis crítico discursivo.

Keywords: Theatre, memory, identity, critical discourse analysis.

\begin{abstract}
"Estaba soñando con los ángeles que bajaban de los cerros de Valpo, mi reina. $Y$ de repente todo desaparecía y sólo quedaba un auto grande y coludo manejado por un demonio gordo y calvo que se me venía, se me venía...! ; Y yo estaba paralizado y transpiraba y transpiraba!; y en eso se me aparece un angelito vestido de obrero que me dice: 'No se asuste compadre, que el miedo es la escopeta que usa el demonio. Si usted no se asusta estaremos siempre juntos. Nosotros bajaremos de la historia cada vez que sea necesario. Bajaremos como en sueño de la memoria.'" (Díaz y Sharim, comp., 2002).
\end{abstract}

Al parecer, la carne cobra cuerpo al teñirse ésta de discurso. Se siente uno 'alguien' diferenciable y situado entre otros al tener la certeza de que se tiene una memoria ${ }^{1}$, una identidad. Y si nos empeñamos en recordar, en revisar los hilos que tejieron nuestro carácter, encontramos sensaciones sujetando palabras. Podemos hablar acerca de lo que somos, siguiendo el mapa que el cuerpo nos traza, al traer otra vez al corazón aquellas marcas que nos dejó la experiencia.

\section{II}

La historia del arte teatral en Chile ofrece etapas en las que es posible ver con claridad distintos pasos dirigidos por nece- 
sidades y fines también diferentes. Como un arte múltiple que funde la expresión en casi todos sus soportes, sostiene una relación particular e inmediata con el público, relación que, junto con la historia, ha tomado variados matices, llegando a permitir la emergencia de voces silenciadas o desplazadas.

Durante los años previos al golpe de estado, el teatro se encontraba muy ligado a las organizaciones estatales y paraestatales (Hurtado y Barría, comp., 2010, 17). Esta situación les reportaba una importante estabilidad económica sobre la cual su trabajo podía sostenerse y desarrollarse. Una parte relevante de su labor estaba ligada a las instituciones educacionales, como las universidades tradicionales, y en su seno se desarrollaron grandes grupos teatrales que llevaron el nombre de la organización que les cobijaba a donde fuese que su trabajo los llevase. El teatro universitario, así, gozó de un importante desarrollo e influencia durante las dos décadas que precedieron al golpe.

La mañana del 11 de septiembre de 1973, la violencia se instaló en el horizonte del país. Se situó en La Moneda, cubriéndola de bombas y fuego, y desde ahí sus largos dedos se apresuraron en alcanzar todo centro de poder en el país. Uno de ellos pertenecía a la cultura. Ésta se erigía ante los ojos militares como un nicho de especial interés, pues trabajaba estrechamente junto a la educación, la producción y la reproducción del conocimiento y la identidad ${ }^{2}$. Las universidades, entonces, no tardaron en ser ocupadas. Se las identificó como lugares peligrosos en donde anidaba el pensamiento sedicioso, y de inmediato se procedió, por medio de interrogatorios, detenciones y listas negras, a tomar por la fuerza el control institucional desde las capas más altas. Estas prácticas autoritarias dejaron enormes mermas en el grupo humano de intelectuales y artistas que participaban del trabajo universitario, ya sea como académicas o académicos, o como parte del alumnado: "Las rectorías, los decanatos, las jefaturas de departamentos se vieron invadidas de súbito por una espesa nube de generales, coroneles, mayores y capitanes cuya tarea prioritaria fue la detección y expulsión de profesores y alumnos desafectos." (Rojo, 1985, 26).

Numerosas garantías estatales destinadas al apoyo de la cultura, las artes y la educación fueron suprimidas o reformuladas, de acuerdo al nuevo modelo económico ultraliberal ${ }^{3}$ del gobierno de facto. Para el teatro, este proceder resultó ser particularmente nocivo. Quienes gozaron de un espacio laboral esta- 
ble en alguna universidad o grupo teatral, perdieron de inmediato dicha oportunidad, desvaneciéndose con ella la posibilidad de reinserción, pues el gobierno autoritario desmanteló casi la totalidad de los lugares en donde antes se trabajaron estas artes. Un inmenso número de actores, actrices profesionales y estudiantes de actuación debieron vivir este desarraigo. Grínor Rojo, en su publicación del año 1985, completa alrededor de cinco planas en el ejercicio de registrar a estudiantes, actores, actrices y compañías completas que debieron dejar el país debido a los distintos atosigamientos a los que fueron sometidos. En su texto procura mencionar el que aún no contaba con un número exacto que pudiese brindar una idea total y certera de la magnitud del éxodo actoral que dichas ordenanzas provocaron, pero su escritura logra sugerir que el daño causado cobró magnitudes muy superiores a las que él podía registrar ${ }^{4}$.

Las artes teatrales resultaron particularmente diezmadas por la represión militar ${ }^{5}$. El teatro es una práctica comunitaria que requiere de un trabajo desarrollado por grupos, para ser ofrecido y compartido por otras y otros que acudirán a las instancias específicas en las que éstos se presenten. El desmembramiento de los grupos teatrales, entonces, no sólo reporta un daño para quienes se involucran en el ámbito, pues su falta repercutirá en una amplia parte de la sociedad. Una representación teatral compromete a distintos actuantes, incluyendo a la audiencia, quienes desde perspectivas disímiles participan de una instancia colectiva que reafirma y constituye la cohesión social, la pertenencia y el sentido de identidad. Una obra teatral representada en el escenario frente a un público es en sí misma una experiencia que ocurre de manera inmediata e irrepetible (Taylor, 1973), lo que conforma una memoria que unirá a quienes estuvieron presentes durante aquel evento.

En esto es que radica, quizás, el peligro que el teatro representaba para el gobierno autoritario instalado en el poder por la fuerza de la represión. Para ellos era fundamental suprimir por completo todo aquello que pudiese traer nuevamente al pensamiento un pasado ominoso que debía sepultarse para siempre.

Las fuerzas autoritarias, entonces, abocaron su poderío violento a instalar la desaparición de la gente de teatro asociada a la historia proscrita, involucrando en esto no sólo su eliminación física, sino también la supresión de su imagen (Hurtado y Barría, comp., 2010, 17), es decir, de su existencia en la conciencia 
colectiva. Las listas negras que comenzaron a circular por todos los medios de difusión, prohibían terminantemente emplear a todas y todos quienes figurasen en ellas. Este intento de borrar en vida a aquellos hombres y mujeres, parece mostrarnos hoy que su imagen pública había trascendido y se había convertido en un significante demasiado peligroso, y por ende, prohibido.

Toda esta situación represiva en extremo cimentó las bases de un terror que pareció abrazarlo todo, desde el ámbito artístico hasta lo más íntimo de muchos hogares. Este sentir petrificante sumió a la sociedad chilena en un oscuro y contenido silencio:

El aislamiento, la atomización, el silenciamiento, el disciplinamiento, la falta de recursos económicos e institucionales fueron desmovilizadores en extremo, con consecuencias psico-sociales traumáticas. Trauma sobre trauma, estos se sumaban a los provocados por las prisiones, torturas, exilios, desapariciones, asesinatos, redadas policiales, amenazas, conculcación del estado de derecho, suspendiéndose este clima sobre parte de la población como una sombra omnipresente. (Hurtado y Barría, comp., 2010, 17).

\section{III}

La actividad teatral, inmersa en la lógica autoritaria del gobierno, se dividió. Parecían existir dos posibilidades. Una, producir un trabajo que no llevara marca alguna de disidencia, y que, como tal, pudiese aspirar a la venia de los censores culturales, o abocarse a un trabajo discrepante del orden establecido, con los riesgos que ello representaba. En esta situación proliferaron las obras que la comisión de gobierno calificó como "de valor cultural", entre las que se encontraron un gran número de obras clásicas, puestas en escena para que el gobierno pudiera ufanarse de tener "buen teatro" (Rojo, 1985, 40) en sus salas, evitando así la proliferación de discursos disidentes sobre las tablas.

La voz crítica del teatro opositor se mantuvo anudada por algún tiempo, luego del 11 de septiembre de 1973. Pero un grito jamás deja de resistirse entre los lazos que los aprisionan en el pecho, y como una exhalación vital atraviesa los labios. Hacia fines de 1975 y principios de 1976, comienzan a sentirse los primeros brotes de un teatro soterrado: "Es ese el tiempo del miedo, de las palabras a medias, de la persecución y el hambre acerbos. Los teatristas chilenos deben encontrar primero una fórmula que les permita sobrevivir. Después aprenderán a hablar de nuevo, a recobrar paulatinamente la voz sofocada por los desbordes del 
odio." (Ibíd., 42).

El 26 de mayo de 1976 se estrena Pedro Juan y Diego, obra de ICTUS y David Benavente. Esta puesta en escena despierta la atención del público, pues propone un teatro que distaba de lo que hasta el momento se había visto. Lo sugerente de su contenido y sus personajes no descansaba en lo nuevo o lo diferente, sino en lo propio. Esto convocó a un número muy importante de espectadores que rieron y se encantaron profundamente con la historia de estos seres que podrían aparecer a la vuelta de la esquina ${ }^{6}$.

Una problemática común de aquel entonces, la cesantía, que comenzaba a golpear muy fuertemente a la sociedad chilena, producto del desenvolvimiento económico del régimen, aparece con fuerza sobre las tablas, y el tema del trabajo se erige en la obra como acción central. Desde lo cotidiano, entonces, podemos ver que sobre el escenario se le da cabida a lo actual, y comienza, de esta forma, a visibilizarse por fin una realidad que permanecía oculta.

De este modo, el arte teatral una vez más soltó su voz, volviendo a montar aquel espectáculo hermanante, ritual y catártico del que es protagonista. Conviene, en este momento, traer las palabras de María de la Luz Hurtado, que se refiere al fenómeno de Pedro, Juan y Diego como sigue: "Y, también como la muda, es esta una parte importante de la recuperación del habla de aquellos que quedaron sumidos en el silencio. La perplejidad es capaz de encontrar un lenguaje: el de una forma teatral, que abre el camino a muchas otras obras y autores en el período." ${ }^{7}$

\section{IV}

Dentro del período al que nos hemos abocado, podemos encontrar numerosas obras que encierran un valor trascendente, tanto para el desarrollo del arte teatral como para la sociedad chilena. Algunas de las compañías profesionales que desarrollaron un trabajo crítico de trascendencia artística, política y social son Teatro La Feria, Teatro ICTUS, Taller de Investigación Teatral TIT, Teatro Imagen y Teatro El Aleph, por mencionar a algunos. En esta ocasión he decidido analizar tres obras, montadas por dos de las compañías recién mencionadas: Pedro Juan y Diego (1976) y Tres Marías y una Rosa (1979), del taller de experimentación teatral TIT; y Lindo país esquina con vista al mar (1979), del grupo ICTUS.

Como vimos antes, Pedro, Juan y Diego marcó el nacimiento 
de una nueva forma de expresión teatral que venía a romper un silencio impuesto por la cruenta represión de la dictadura sobre el país. Tres Marías y una Rosa y Lindo país esquina con vista al mar, son también exponentes de esta nueva voz que erige un discurso silenciado, a través de una codificación discursiva diferente. Entre las nuevas significaciones que aparecen en esta situación teatral específica podemos observar que aparecen en escena elementos cotidianos que expresan mensajes profundos, críticos y disidentes.

Esta forma teatral mantiene una relación muy directa con el público que acude a sus representaciones. Los hombres y mujeres espectadoras comprenden que lo que ven sobre el escenario cumple un rol político y social profundo, que restaura el sentimiento de pertenencia y de expresión colectiva perdida. Así, el acto teatral se convierte en un rito catártico reconstituyente y esperanzador, que codifica un mensaje escindido, negado, eliminado de los espacios que el gobierno permite y hace visibles. Es así como surge una nueva manera de codificar y decodificar la expresión:

Con el perro de la censura en la sala, sentado en las butacas de la imaginación pura, pero olfateando a cada minuto la metáfora, la única posibilidad que al grupo le queda es el trovar clus. Trovar clus que por lo que llevamos dicho no implica como otrora un culto de la oscuridad por el pedantesco prurito de la "dificultad docta", ni mucho menos, sino que el ejercicio de una autocensura, que es paralela a la censura oficial, pero que al contrario de esa otra se resuelve o puede resolverse positivamente a través de la representación de un espectáculo en el que las palabras, la práctica de la escritura, y los gestos, la práctica escénica, dicen sin decir. El público cómplice escucha más allá de las palabras y ve más allá de los gestos; descifra, incluso, los silencios. Palabras, gestos y silencios se constituyen finalmente en una forma de lenguaje rebelde, desalienado y en pugna con el lenguaje del fascismo. (Rojo, 1985, 48).

En el campo de la cultura, el ejercicio del control y la dominación obedeció a mecanismos directos e indirectos del abuso ${ }^{8}$ más cruento. La magnitud de esta práctica tuvo consecuencias traumáticas nefastas y evidentes en el campo de las artes teatrales, traducidas -como hemos visto- principalmente en el silencio y la disgregación de espacios comunitarios. Sin embargo, la resistencia se atrincheró también desde estas prácticas indirectas, a través del uso del lenguaje y las artes expresivas. Así, frente 
a un discurso hegemónico y autoritario que erige su voz como mensaje único, se codifica una manifestación opuesta, que utiliza una expresión diferente y compleja que consigue hablar a través de un reordenamiento de símbolos, nombrando sin nombrar, al no acogerse a las normas que el discurso oficial controla.

En este punto, resulta relevante observar los planteamientos de Michel Foucault. En ellos podemos observar las dimensiones múltiples que un discurso puede cobrar. El discurso hegemóni$\mathrm{co}$, que se impone como verdadero, se erige como signo y herramienta, en un acto performativo ${ }^{9}$, reproduciéndose a sí mismo a través de las prácticas y comportamientos de los sujetos. El discurso hegemónico cimienta su propia existencia al calificar sus prácticas positivamente, reproduciéndolas, y al descalificar a las disidentes ${ }^{10}$. De este modo, y a través de distintos dispositivos, la dominación se provee a sí misma de marcos de referencia adecuados, como quien construye un contexto coherente para sus actos. El poder se auto-promueve, a través del discurso y los sujetos que lo reproducen. De este modo, la disidencia sólo puede erigir su voz por medio de una nueva codificación re-significadora, dejando huellas de la propia enunciación en una codificación diferente.

\section{Pedro, Juan y Diego (1976)}

ICTUS montó esta obra teatral en la sala "La Comedia", en marzo de 1976. En ella encontramos a tres hombres que acarrean piedras desde el foyer hasta el escenario en rápidas y constantes carreras. Se encuentran en el medio de un terreno desocupado y periférico, cerca de una mediagua en donde vive sola una mujer muda. Se les ha ordenado construir un muro, una pirca de piedra, en medio de aquel peladero, como muro de contención para obras viales posteriores.

Pedro es un maestro de construcción cesante, con varios años de experiencia; Juan es un pequeño comerciante de frutas y verduras quebrado; y Diego es un funcionario público "exonerado por reducción de personal" (ICTUS et al., 1989, 302). La cruda situación de cesantía en la que se encuentran, los ha empujado a optar por un programa gubernamental de trabajo precario. Sin que en la obra se mencione, el público puede apreciar que los personajes forman parte del PEM (programa gubernamental de empleo mínimo), organización bien conocida en aquel período. 
Grínor Rojo adscribe al texto una dimensión íntima que no sólo refleja la realidad de una parte importante de la sociedad de aquel momento, sino también a la realidad del teatro, en relación a dicha situación:

...en ella había algo así como una declaración de principios, especie de manifiesto de un teatro distinto y cuya máxima novedad consistía menos paradójicamente de lo que parece a simple vista, en la falta de novedad del asunto. Lo inhabitual (...) no lo era en el fondo con respecto a la realidad de verdad, la de afuera, la de la calle, sino que con respecto a la realidad del teatro, el teatro que se venía haciendo en Chile desde el golpe y aquel que -como quiera que sea, nos topamos aquí una vez más con el problema de la magnitud de la ruptura-, se había hecho antes de él. (Rojo, 1985, 43).

El eje central de la obra es el trabajo, que se desarrolla continuamente produciendo fatiga real en los actores. Los personajes deben construir la pirca que se les ha encomendado, sin importar la evidente incoherencia que dicho mandato encierra. En tal proceso, además, deben sortear una serie de obstáculos que no hacen más que demostrar el ínfimo valor y consideración que los dirigentes tienen por su labor. Todo en aquella situación es incongruente, ya que el esfuerzo de aquellos hombres se destina a una tarea absurda.

De este modo, la obra teatral logra situar en escena una problemática cotidiana de gran contingencia. La cesantía, por aquellos años, se había instalado en un gran número de hogares chilenos, y aquel día de marzo, finalmente, aparecía bajo la luz pública. Este hecho sorprende a la audiencia desde la primera escena, en donde encontramos a Juan, quien discute con Don Carlos por las medidas de seguridad en el trabajo. Este último le amenaza con el despido:

JUAN: ¿Dónde te metís la plata de los guantes, viejo maricón? DON CARLOS: Hay más de doscientos chascones haciendo cola en la oficina, esperando trabajo. Así es que ándate con cuidadito. (ICTUS et al., 1989, 28)

Como podemos ver en este breve extracto, el lenguaje utilizado en la obra es de carácter coloquial y cotidiano. Éste, junto con el trabajo real que se desarrolla durante toda la representación, reproduce en escena aquella realidad que sólo podía verse en las periferias. Patrizia Violi en El infinito singular, describe esta capacidad creadora en las siguientes palabras: "El lenguaje como 
sistema que refleja la realidad social pero que al mismo tiempo la crea y la produce, se convierte en el ámbito en el que la subjetividad toma forma y consistencia, desde el momento en que el sujeto solamente se puede expresar dentro del lenguaje y el lenguaje no puede constituirse sin un sujeto que lo haga existir." (Violi, 1991, 13).

De este modo, nos encontramos con una obra particular que presenta un entretejido lingüístico cuyas características discursivas permiten la presencia de profundas reflexiones ocultas entre sus pliegues. En el escenario, la audiencia encuentra a tres personajes que entremezclan la comicidad y el drama, insertos en un contexto de trabajo. Así, entre conversaciones que involucran lo laboral y lo cotidiano, podemos encontrar líneas en las que nos parece ver emerger mensajes disruptores, como el siguiente:

JUAN: Es raro ese gallo, ah?

PEDRO: Raro es...

JUAN: Pa'todas partes sale pegando con la maleta, ¿se ha fijado? ¿Qué andará trayendo ahí?

PEDRO: $\mathrm{Pa}^{\prime}$ mi que es periodista...

JUAN: ¿Escritor, dice usted?

PEDRO: Periodista. De esos que los mandan a sapear para que después escriban sobre lo que pasa. $\mathrm{Pa}^{\prime}$ la población donde yo vivo han ido varios. (ICTUS et al., 1989, 41-42)

En este extracto, Juan y Pedro comentaban acerca de la maleta que Diego siempre llevaba con él. Este elemento le servía a Diego para mantener la apariencia de trabajar aún en la oficina de la que había sido despedido frente a su mujer, y para llevar los documentos de un negocio que esperaba concretar. Así, la extrañeza de los otros dos personajes es utilizada como un marco de referencia particular que oculta la denuncia que la enunciación contiene. En este enunciado se refleja la vigilancia que el gobierno autoritario mantenía en los sectores más pobres de la sociedad; vigilancia particularmente cruenta y constante, en la que varias y varios pobladores resultaron desaparecidos.

Teun Van Dijk utiliza, entre las herramientas del método de análisis crítico del discurso, la manipulación de ítemes léxicos para persuadir al receptor o lector, e influir en la comprensión que éste o ésta tengan acerca del hecho referido. En la obra que en esta ocasión analizo, la estrategia léxica que podemos encontrar no corresponde a la calificación positiva o negativa del otro, sino 
a la utilización de un vocablo diferente, coherente sólo para el contexto del enunciado, desde donde se evidencia un significado distinto de la denotación inmediata del ítem léxico. Este ejercicio logra su fin comunicativo al dejar emerger el carácter de la enunciación contenido en aquel tejido discursivo, no por medio del uso evidente de la fuerza denotativa de los vocablos, sino por el desarrollo dinámico del discurso en la acción dramática. Las palabras son usadas para encubrir, mientras los silencios y las intencionalidades que cargan los diálogos logran finalmente entregar la fuerza enunciativa del discurso latente. Éste emerge provocando un impacto particular, que parece atravesar la carne y romper la quieta estabilidad racional del cotidiano en el que la audiencia se ve envuelta. Aquellos diálogos, representados durante los días del año 1976, deben haber resonado como balazos en los pechos de quienes veían y comprendian entre líneas.

El ACD también se aboca al análisis de textos y contextos en sus investigaciones. El discurso se constituye como tal en contextos sociales políticos e ideológicos. Este hecho no puede ser ignorado, ya que éstos funcionan como marcos referenciales necesarios para la comprensión cabal de su contenido. (Van Dijk, 1996, 23). En una obra teatral, en donde una realidad es recreada en escena, los marcos referenciales que permiten la intelección cabal de su argumento involucran, tanto al momento histórico, político y social específico de su representación, como al contexto situacional que se crea en sus textos teatrales. La realidad del momento de la representación es tan relevante como la realidad ficcionalizada de la obra dramática. Así, en el extracto de Pedro, Juan y Diego que acabamos de observar, se manipula la situación como un subterfugio de ocultamiento, con el fin de dejar emerger un enunciado impelente.

En Pedro, Juan y Diego es posible encontrar, además de la estrategia discursiva antes mencionada, metáforas que apelan a la audiencia con fuerza. Una de ellas la personifica el personaje de María, la mujer muda con quien los personajes instauran una bella relación de amistad:

DIEGO: ¿Cómo fue que se quedó muda?

PEDRO: Por un susto muy re'grande que tuvo.

DIEGO: ¡¿Cómo iba a quedar muda por un susto, hombre por Dios?! (ICTUS et al., 1989, 33)

Este personaje encarna al mundo de las artes y al grupo de ciudadanos disidentes al régimen quienes, presa del trauma y 
la brutal represión existente, se ven impedidos de manifestar públicamente su pensar. Una nueva alusión a la imposibilidad de ocupar las calles, aparece enmarcada en una ensoñación que los personajes encumbran mientras piensan y analizan la posibilidad de instalarse en el negocio de la fotografía, en la rotonda Kennedy, sector acomodado de la ciudad-capital:

DIEGO: Mil cuatrocientos cuarenta y nueve punto seis. Castíguelo, y déjelo en mil cuatrocientos autos parados.

JUAN: ¡La media colita de autos! Van a llegar hasta la Plaza Italia.

(La señora María entra a su casa a disfrazarse.)

DIEGO: ¿Promedio de pasajeros por auto parado? Dos coma dos. Castíguelo, y déjelo en dos, lo que da dos mil ochocientas personas paradas.

JUAN: Ahora, castíguelos y llévelos presos por huevones.

DIEGO: Podría ocurrir, también. (ICTUS et al., 1989, 82)

Estos últimos extractos nos permiten ver la presencia de un discurso latente que se alza hasta abarcar grandes y fundamentales problemáticas, como la situación del arte y el pueblo reprimido. Así, la obra representa una dimensión invisibilizada de la realidad chilena del momento y, además, ofrece una luz de esperanza que invita a la redención y a la recuperación de la propia voz y expresión. María, el personaje que encarnó a las artes durante toda la obra, recupera finalmente la capacidad del habla y entona una canción junto a sus amigos, hacia el final de la obra dramática. El mensaje latente que la obra teatral entrega a su audiencia finaliza con un llamado a la recuperación y la liberación.

\section{Tres Marías y una Rosa (1979)}

Tres Marías y una Rosa se estrenó en julio de 1979, en la Sala "Del Ángel". Surgió del trabajo colaborativo desarrollado por el Taller de Investigación Teatral TIT y David Benavente.

Al igual que Pedro, Juan y Diego, esta obra se instala en la base de la situación de cesantía que el país atravesaba. Esto nos invita a relacionar reflexivamente ambos trabajos dramáticos, ya que nos muestran distintas perspectivas de una problemática general. La primera nos retrata dicha tensión a partir de la experiencia masculina. En ella vemos la pérdida de la dignidad que la falta de trabajo -o el trabajo precario que, lejos de dignificar, diezma la situación de los personajes- le otorga al hombre, relegándolo a los límites de lo social. 
El fenómeno de la cesantía, en el caso de los hombres, se vive en la calle. Los trabajos precarios a los que pueden optar los obliga a permanecer en los espacios abiertos de la periferia, desde donde su intimidad y carencia se proyectan en escena. Así, este ámbito sirve como plataforma para alzar una voz de despertar, que reclame libertad desde una precariedad social, en y desde las calles.

Tres Marías y una Rosa lleva a la audiencia a internarse, nuevamente, en el mundo de la cesantía, pero desde lo privado. Se accede así a la realidad íntima de las mujeres que viven la cesantía de sus maridos, o la ausencia de éstos. Maruja, María Ester, María Luisa y Rosita son cuatro mujeres que practican el arte de las arpilleras. Esta labor es para ellas una posibilidad de obtener dinero extra para el sustento de sus hogares y sus hijos, pues sus trabajos son ofrecidos para la venta en el extranjero.

El ámbito laboral nuevamente se erige como el núcleo central de la obra. Como en Pedro, Juan y Diego, los personajes realizan su actividad sobre el escenario, y enfrentan las problemáticas propias que un trabajo comunitario de esta naturaleza puede reportar. Así, se dispone una acabada representación de la realidad que muchas mujeres poblacionales enfrentaban: ellas deben cuidar de los niños (los que ya tienen y los que vienen), deben cumplir con todas las tareas propias del hogar, deben atender a sus maridos (quienes los tienen) y deben, además, conseguir dinero extra, ya que sus cónyuges carecen de empleo. De este modo, y a partir de estos personajes en contexto, la obra teatral transporta a las y los asistentes, al mundo femenino en la precariedad.

Tanto Tres Marías y una Rosa como Pedro Juan y Diego, han sido escogidas como corpus del presente artículo, debido a que ellas entregan representaciones análogas de una problemática básica del momento histórico en el que surgieron. Discursivamente, por manejar contextos hermanos, dejan emerger mensajes sociales fundamentales, con una fuerza similar y poderosa. Sin embargo, he decidido abordarlas de manera diferente, ya que quisiera intentar evidenciar dos de las dimensiones que el discurso performativo tiene.

Como dije anteriormente, Pedro, Juan y Diego representa el problema de la cesantía desde una perspectiva masculina, lo que invariablemente lleva a la audiencia a situarse en espacios públicos. Quise, entonces, hacer una analogía entre estos espacios 
públicos y la presencia de la palabra en el tejido expresivo y, por ello, procuré analizar lo dicho por los personajes y los mensajes que con estos enunciados se comunicaron. Tres Marías y una Rosa, por otro lado, retrata la problemática de la cesantía desde lo privado y, en consecuencia, siguiendo con la relación que me propuse anteriormente, intentaré esta vez, no analizar el discurso a partir de las palabras utilizadas, sino abocarme al mensaje que la obra entrega por medio de la performance corporal y/o escénica ${ }^{11}$.

En Tres Marías y una Rosa es posible distinguir tres momentos importantes, en los cuales los personajes representan situaciones que escapan a la naturaleza de la realidad en la que se ven inmersas. Uno de ellos involucra la danza de la cueca; otro, el rito del matrimonio; y el último, la confección y exposición ante el público de una arpillera gigante elaborada de manera colectiva. Estas actuaciones se acercan al rol que el juego tiene para los seres humanos. Así, el imaginar o el acto de vestirse como otros les da a los personajes una posibilidad catártica y carnavalesca de mitigar sus carencias, afianzar lazos y recobrar energías, de modo que la precaria realidad en la que viven les resulte más llevadera. Las representaciones que encontramos en Tres Marías y una Rosa también encierran estas características. Sin embargo, ellas parecen ir más allá, ya que, a través de su ejecución, un discurso latente y femenino logra emerger, encarnando muchas de las problemáticas globales que un importante número de mujeres debe enfrentar.

Durante el cuadro cuarto, encontramos a los cuatro personajes nuevamente reunidas en torno al trabajo, tras haber solucionado rencillas pasadas. Esta vez deben comenzar la confección de una arpillera gigante que el sacerdote extranjero del sector les ha pedido, para la inauguración de la nueva capilla. Por ello, cuentan con una cantidad importante de tela que deben clasificar. Mientras realizan esta tarea, la fascinación limpia del juego se apodera de ellas, inspiradas por el hallazgo de una tela blanca que las hace recordar el día de sus matrimonios. Rosita, la menor de ellas, con un avanzado embarazo, no tuvo oportunidad de casarse por la Iglesia. Frente a esto, todas sucumben ante la tentación imaginativa de representar su matrimonio religioso.

Utilizando los trapos nuevos con los que cuentan, como niñas vistiendo a una muñeca, confeccionan un vestido que representará la imagen mixta de una novia, que recuerda mucho a la Virgen de Lourdes. Comienza el juego y todas cubren un rol, 
con el fin de que la ceremonia se realice de manera íntegra y de acuerdo a sus deseos. Maruja interpreta al novio y al padrino, María Ester al cura (que es en realidad una sacerdotisa) y María Luisa a la Madrina.

En este juego performativo, las cuatro mujeres subvierten el orden de género y con él, del poder. Una ilusión como ésta les permite total libertad imaginativa, y ellas se rinden dichosas. Así, María Ester decide que representará a una monja en vez de a un cura y, frente a la observación de Rosita en donde ésta le recuerda que las mujeres religiosas no tienen la facultad de oficiar el matrimonio, María Ester simplemente responde: "es que este es un matrimonio moderno" (ICTUS et al., 1989, 229) y, de este modo, permite que el flujo creativo de la actividad catártica que realizan, continúe.

A través de esta bella representación las cuatro mujeres construyen performativamente un contexto, una realidad ficcional, a partir de la cual emergerá un discurso latente disruptivo que denunciará las múltiples y cotidianas represiones a las que una mujer debe someterse de acuerdo a las leyes y el patriarcado:

MARÍA ESTER: (Engrosando la voz) “¿Habéis venido a uniros en matrimonio?"

MARUJA: (Da un codazo a Rosita) "Sí".

ROSITA: Sí.

MARÍA ESTER: Señora Rosa Martínez...

ROSITA: Sí

MARUJA: No se contesta sí

MARÍA ESTER: “Señora Rosa Martínez, ¿acepta seguir a este hombre en el dolor, la adversidad, la desgracia, la miseria, el hambre y los terremotos?"

ROSITA: No

MARÍA ESTER: “¿Acepta que la cachetée, que le ponga el gorro, que la llene de chiquillos, que no traiga plata pa' la casa, que llegue curao?"

ROSITA: No

MARÍA LUISA: ¡Así me gusta! (Ibíd., 232-233).

Esta ceremonia comienza a hilarse de acuerdo a los deseos comunes de todas, y a medida que el disfrute del imaginario aumenta, todas tienen igual acceso a los turnos de habla y terminan por enlazar un diálogo liberador para todas:

MARÍA ESTER: “¿Promete que después de ocurrido el hecho, hacerle por lo menos un cariñito?"

TODAS: ¡Sí! ¡Sí! ¡Sí! 
MARÍA ESTER: "Entonces en ese caso..."

TODAS: ¡De nuevo! ¡De nuevo!

MARÍA LUISA: Pídale que le ayude a educar a los cabros, señor cura.

MARUJA: Y que le ayude a arreglar la casa también.

MARÍA LUISA: Y a no enojarse porque hace arpillera. (Ibíd., 233-234).

Ellas desmontan el discurso de poder imperante, gracias a las posibilidades infinitas que les entrega la catarsis del juego y la representación. Y aunque el ensueño es bruscamente interrumpido por los gritos del Negro, que exige ayuda para bajar unos paquetes, una sensación de secreto bienestar y compañerismo las embarga por igual. Rosita culmina este cuadro con una última línea, que expresa la sencillez de la alegría que el rito de compartir deja en sus corazones:

ROSITA: estuvo linda la fiesta ¿ah? (ICTUS et al., 1989, 235)

Hacia el final de la obra, una vez que el trabajo de la arpillera ya se encuentra avanzado, la audiencia tiene la oportunidad de presenciar un performance completo que involucra; tanto la exhibición de la arpillera gigante, confeccionada durante las escenas transcurridas; como la presentación de una cueca que ellas han preparado, con motivo de la inauguración de la capilla. La arpillera ha sido confeccionada en torno a la temática del juicio final y, mientras se presenta la arpillera ante el público, Maruja baila la cueca sola, al son del canto de sus compañeras:

TODAS: Con empanás, jay sí!

$\mathrm{Pa}^{\prime}$ regodearse

Porque el Juicio Chileno

Tiene que darse

$¡$ ¡Huifa ayayay!

Juicio Final, jay sí!

Juicio del bueno. (Ibíd., 268-269)

De este modo, el discurso cobra dimensiones performativas que involucran la expresión corporal, musical y visual a lo verbal, codificado en una canción. Todos estos elementos, en activo ejercicio sobre el escenario, permiten la revelación del discurso político latente, que por fin emerge como una epifanía. Éste denuncia la existencia patente de los detenidos desaparecidos y de sus mujeres, a través de la imagen de Maruja bailando la cueca sola, y exige justicia para el sector de la población que vive y empatiza con este hecho. 


\section{Lindo país esquina con vista al mar (1979)}

Lindo país esquina con vista al mar fue creada conjuntamente por Marco Antonio de la Parra, Darío Osses y Jorge Gajardo, en una creación colectiva de ICTUS. La estructura de esta obra distaba mucho de lo tradicional en el momento de su estreno. Está compuesta por cinco cuadros independientes. Sus temáticas no están relacionadas de manera lógica o narrativa, por lo que aparecen, a simple vista, como cuadros distintos e inconexos.

La escenografía utilizada es sumamente minimalista, por lo que la acción dramática se construye por medio de la expresión corporal y el uso específico de elementos. No existe presencia de un trío o cuarteto constante de personajes que deban desarrollar una acción en escena, sino que se suceden distintas historias como acontecimientos paralelos, llevados a cabo por personajes diferentes. Salvo ciertos guiños que pueden encontrarse en el atento diálogo de algún personaje recordando la buena o mala fortuna del otro, en un pasado distante a su presente, no existe relación lineal alguna que pueda proponer la tesis de una continuidad lógica entre ellos.

En esta característica fundamental radica la razón por la cual he escogido esta obra como la última pieza de mi corpus. Su constitución heterogénea podría sugerir la presencia de una figura desmembrada, carente de lógica, cuyo discurso inconexo no lograría ajustarse con claridad a los requerimientos del lenguaje. Este seccionamiento, sin embargo, se erige como la trama perfecta si lo que se quiere es encubrir un discurso latente disruptor. El trabajo de ICTUS comprueba esta impresión con creces ${ }^{12}$. Toda aquella disociación sugiere la expresión de la locura o el sueño, encontrando en esta evocación una posibilidad contextual de lectura que beneficiaría el artificio del ocultamiento. Michel Foucault, al referirse a la locura, señala:

Desde la más alejada Edad Media, el loco es aquél cuyo discurso no puede circular como el de los otros: llega a suceder que su palabra es considerada como nula y sin valor, no conteniendo ni verdad ni importancia, no pudiendo testimoniar ante la justicia, no pudiendo autentificar una partida o un contrato, no pudiendo ni siquiera, en el sacrificio de la misa, permitir la transubstanciación y hacer del pan un cuerpo; en cambio suele ocurrir también que se le confiere, opuestamente a cualquier otra, extraños poderes, como el de enunciar una verdad oculta, el de predecir el porvenir, el de ver en su plena ingenuidad lo que la sabiduría de los otros no puede percibir. 
Así, esta estrategia dramática permite la expresión de contenidos disidentes, al evocar la presencia de un discurso válido e inválido a la vez. De este modo, el trabajo que ICTUS presenta podría ser percibido como una obra de carácter incoherente, carente de estructura y relevancia. Sin embargo, la misma característica es un recurso incorporado con mucha anterioridad a los años setenta, como una característica formal propia del ámbito estético. Podemos observar dicha ruptura estructural en los trabajos de Jorge Díaz o incluso en Huidobro; todas ellas obras muy alejadas de las posibilidades intelectuales que los censores de la dictadura militar chilena pudiesen manejar. Una audiencia como aquella quizás interpretaría la obra de manera somera, sin llegar a percibir la fuerza crítica de su enunciación. Y asimismo, aquellas y aquellos que, por el contrario, logran comprender el discurso latente que la obra expresa, observan un trabajo de importantes implicancias a partir de la misma obra teatral.

De este modo, Lindo país esquina con vista al mar erige su voz a partir de una estructura formal atípica. Esto, sumado a los contextos aparentemente apolíticos en los que los distintos cuadros se desarrollan, posibilita un mecanismo de ocultamiento eficaz para su discurso latente.

He decidido abocarme con especial énfasis al último cuadro de la obra, con el fin de observar en detención la hábil estrategia discursiva que ICTUS desarrolla. El episodio lleva por nombre "Toda una vida" y se desarrolla en las dependencias de un hospital.

La situación laboral de las enfermeras Leonor -una mujer madura con varios años de servicio- y Marilín -mujer que cuida su apariencia joven, ocultando su carnet de identidad y falseando su edad- salta a la vista. La globalización, fenómeno emergente en el momento histórico en el que la obra era representada, se ve retratada a través del humor, de manera reveladora y escalofriante. Dicha escena presenta una profunda y dinámica reflexión en torno a la situación que muchas y muchos trabajadores viven, al estar insertas/os en el tránsito vertiginoso del "crecimiento económico" y la instalación del neoliberalismo. En el transcurso de los diálogos vemos que este afán posmodernista representa, en el fondo, una peligrosa amenaza. Una renovación del hospital podría traer consigo grandes cambios en el personal, y ellas podrían ser reducidas con facilidad, al no ser ya tan jóvenes.

La posmodernidad, presentada continuamente bajo la ilusión desarrollista, oculta que el proceso de renovación sobre 
el cual descansa incluye la necesaria y convulsiva supresión de lo anterior. Un discurso dominante, erigido como verdadero e inmutable, se instala en lo cotidiano invisibilizando lo nocivo, absurdo y aterrador de sus prácticas. El arte teatral de ICTUS nos muestra una forma indirecta de evidenciar la presencia de aquellos elementos oscuros, naturalizados en el diario vivir. La presencia del humor y el trabajo con situaciones cotidianas, permiten poner en escena estímulos que desmitificarán aquellas situaciones entendidas como objetivas y de carácter inamovible. Muchas de las normas y concepciones sociales existentes se instalan como deberes ineludibles, cuando en realidad descansan en conceptos subjetivos construidos cultural e históricamente, y de acuerdo a una cierta lógica previa. ICTUS hace visible todo aquello en sus trabajos, y María de la Luz Hurtado resume las estrategias que la compañía utiliza en las siguientes palabras:

El humor en el ICTUS es usado para provocar una relación de estímulo constante al receptor, el que por una parte le abre las defensas protectoras que se pone ante la auto-crítica; y por otra, le permite desenmascarar, extrañar o desmitificar normas sociales de comportamiento y de interpretación de la realidad. (Hurtado y Ochsenius, 1980, 83).

La cotidianeidad del hospital y sus personajes es constantemente interrumpida por la presencia de don Eustaquio, un enfermo mental crónico, cuyo pensamiento desarraigado del presente se ha quedado en los momentos más felices de su pasado. Este personaje viaja por la geografía y la historia de Chile durante las décadas de 1920 y 1930. Rememora así el golpe de Estado en septiembre de 1924, la instalación de un nuevo estado socialista, la caída del General Ibáñez y el ascenso de Marmaduke Grove. En sus desvaríos, don Eustaquio construye, a través de un discurso histórico, un lenguaje que le permitirá verbalizar todo aquello que no podía decirse de manera pública en el momento del estreno. El personaje encarna y alza la voz silenciada de las artes y el sector disidente del país.

La locura que el personaje padece le permite desdoblarse en escena, constituyéndose así como un potente canal de denuncia, enmarcado en un contexto cotidiano que le brinda las características necesarias de credibilidad y coherencia a su presencia y discurso. Lo que diga o haga no será considerado con seriedad por quienes le rodean; su mensaje sólo emergerá al situarse él frente a un público que podrá observar los hechos desde sus 
butacas, obteniendo a partir de esta distancia el "extrañamiento $^{\prime 13}$ necesario para comprender el valor de sus palabras:

EUSTAQUIO: Tiene razón, señora Ilusión. Tanto en el triunfo como en la derrota, hay que mostrar una noble faz... Si no, después llega el enemigo, te agarra y iguay de lo que te hace! Mejor no hablemos, que ya todos sabemos. (Díaz y Sharim, comp., 2002, 477).

Las palabras de Don Eustaquio carecen de valor al estar inmersas sólo dentro de la cotidianeidad del hospital en que vive. Su presencia y comportamiento ha sido asimilado como natural y así, los personajes que comparten escena con él no logran comprender el valor significativo de su discurso. En esto el rol del público resulta fundamental, pues es el único capaz de comprender y reflexionar en torno al significado de aquella voz.

La demencia de don Eustaquio, situada en un contexto de medicalización, según lo que dicta el discurso científico de la salud, no representa amenaza alguna para los personajes que le rodean ni para la sociedad en general. Así, este hombre inofensivo ya, tiene permitido hablar de cualquier tema, incluso de política:

EUSTAQUIO: ...Porque tengo mucho interés en saber cómo marcha el trámite constitucional de la enmienda que establece que todo ciudadano tiene derecho a expresar libremente sus convicciones; cualquiera sea su ideología, el partido político en el que milite, o la religión que profese. (Ibíd., 2002, 485).

Sin embargo, don Eustaquio logra nombrar la contingencia de aquel entonces de manera más directa, pero no evidente. En él, ICTUS denuncia, pero bajo el ardid de una fachada histórica distante y una situación que tenderá a desacreditar lo dicho, de acuerdo a la fuerza de las normas sociales.

\section{V}

Don Eustaquio viaja con su mente por lugares recurrentes y comunes. Su pensamiento deambula libre de los lazos que lo sujetarían a un Chile de geografía fija, donde sólo hay un norte y un sólo sur. En el hospital, en la población y en los peladeros, Pedros, Juanes, Diegos, Rosas, Marías y Eustaquios logran emitir mensajes disidentes que debían ser silenciados. Sus palabras y actos dibujan para la audiencia, contenidos sólo visibles a través 
del distanciamiento y la reflexión, como parte de un artilugio crítico y poderoso. En la actualidad estas formas parecen reaparecer, constituyendo una voz que denuncia con fuerza catalizadora. Hoy los censores de la dictadura no visitan las salas de teatro de la misma evidente manera. Los ojos vigilantes parecen estar en todas partes, emitiendo un bullicio ensordecedor que parece sumergir a las mentes en una abulia que disipa los pensamientos, y así, frente a ello, se hace necesario emitir una voz que logre superponerse al ruido imperante. El uso de estructuras atípicas e inconexas forma aún parte de la estética actual. HP de Luis Barrales es un ejemplo de esto. La obra presenta cuadros constituidos en modos muy disímiles que sorprenden a la audiencia en cada aparición, siendo posible su comprensión sólo por enmarcarse dentro de la idea, casi metafórica del desmembramiento y el drama humano que Hanz Pozo debe sufrir, como una metáfora de aquellos grupos sociales que la globalización parece cercenar, en donde nacen, crecen y (sobre)viven cuerpos chilenos, marginales y subalternos.

Shakespeare Falsificado, del mismo autor, es también otro ejemplo relevante. En ella encontramos un texto que entrelaza, en el contexto de una obra teatral perdida y supuestamente falsificada del propio creador inglés, elementos de la historia chilena y latinoamericana reciente, relatada junto a parte de la historia de escocia, en paralelo. Todos estos recursos crean una textualidad compleja y presentan una obra de la que emergen mensajes concretos muy actuales e impelentes, como epifanías, impactando fuertemente en la audiencia que, gracias al distanciamiento que el teatro posibilita, logra leerlas.

Así, podemos ver que el teatro como rito catártico y comunitario, continúa ofreciendo una posibilidad de despertar. Contiene memoria, vida y carne, sin censuras. En su textura encontramos sensaciones sujetando palabras. Y gracias a ello, quienes no compartimos las experiencias narradas podemos acercarnos empáticamente a su discurso. Este arte permite la transmisión de la cultura de un pueblo que, por medio de la experiencia lúdica, ritual y catártica de su representación, logra fijar en su espíritu aquellas sensaciones que la hacen parte de un colectivo múltiple y complejo. 


\section{Notas}

1 Sin embargo, la memoria es frágil y puede perderse llevando consigo la posibilidad de identidad y cohesión que ofrece. En ello radica la importancia del ejercicio del recuerdo. Con respecto a esta fugacidad y a este peligro, conviene citar a Walter Benjamin: "La verdadera imagen del pretérito pasa fugazmente. Sólo como imagen que relampaguea en el instante de su cognoscibilidad para no ser vista ya más, puede el pretérito ser aferrado. (...) Pues [la historia] es una imagen irrecuperable del pasado que amenaza desaparecer con cada presente que no se reconozca aludido en ella." (1995).

2 Diana Taylor define el concepto de performance como actos a través de los cuales se transfiere saber social, memoria y sentido de identidad, a través de acciones reiteradas. (2003).

3 El autor antes citado describe el carácter del gobierno autoritario en las siguientes palabras: "Como se sabe, es éste un modelo ultraliberal en lo económico, si bien extraordinariamente conservador y represivo -con frecuencia hasta atraerse el escándalo del mundo -en lo social, político y cultural." $(1985,26)$.

4 María de la Luz Hurtado, como ilustración a esta oscura situación, menciona que "más del $90 \%$ de los profesores del Departamento de Teatro UCH fue exonerado en esa universidad laica y muchos sumariados, al igual que numerosos alumnos." (Hurtado y Barría, comp., 2010, 17).

5 Sobre aquella impresión reflexiona Rojo: "Por razones que tienen que ver con la esencia del quehacer escénico, con su socialismo necesario, por así decirlo, ya que no hay ni puede haber teatro sin interacción comunitaria, sin el contacto personal, históricamente localizado, entre comediantes y público, el celo represivo fue -y era esperable que lo fuese: no era ésta la primera vez en la historia de las prácticas teatrales que el fascismo se administraba un hartazgo semejante -mayor." $(1985,28)$. Por su parte, David Benavente compara la situación del teatro chileno en dictadura con otras experiencias similares en América Latina. Menciona a Argentina y Uruguay, en donde el teatro fue totalmente diezmado y no hubo representación alguna sobre sus escenarios durante los años en represión. A partir de esta situación el autor concluye que en Chile el teatro no fue golpeado en un modo tan brutal, y que, gracias a ello, logró reconstituirse. $(1989,280)$. Varias son las formas en que un pasado puede cifrarse de acuerdo a la interpretación y las percepciones particulares de un testigo. Así, para quienes no presenciamos los hechos, resulta de importancia vital la observación empática y reflexiva de los testimonios de otras y otros.

En este punto conviene hacer notar que aquellos personajes co- 
munes pertenecían al grupo más precario de la sociedad chilena de aquel momento. Dicho grupo que debió sufrir los durísimos golpes de la cesantía y la depresión económica y su voz y parecer carecían de valor a los ojos de los grupos de poder. Así, los planteamiento de Gayatri Spivak expuestos en su ensayo ¿Puede hablar el subalterno?(Spivak, 1999) resultan relevantes, al retratar a estos grupos como carentes de la posibilidad de habla o de elevar su voz de manera válida y equivalente, frente a los grupos de poder que ejercen su dominación sobre los mismos hablando por ellos.

7 La obra Pedro Juan y Diego presenta entre sus personajes a María, una mujer que ha perdido la capacidad del habla por una experiencia traumática no especificada. A lo largo de la obra, ella logra compartir gratos momentos en una relación de amistad y compañerismo con los personajes Pedro, Juan y Diego, lo que hace que poco a poco recupere el habla y pueda, hacia el final de la representación, elevar su voz por fin, en una canción. (ICTUS et al., 1989, 15).

8 Teun Van Dijk también se refiere al concepto de abuso y lo enmarca en las prácticas de mal uso del poder, entendido éste como el ejercicio de dominación de unos por sobre otros, de manera desmedida. (Ibíd., 26).

9 El concepto de acto performativo utilizado obedece, en este caso, a la definición de Diana Taylor.

10 Teun Van Dijk también se refiere a este hecho, al distinguir entre las distintas prácticas que las / os hablantes utilizan, es decir, a la capacidad de éstos/as de referirse al resto de manera diferente (incitando lecturas diferentes). Un ejemplo de esta práctica puede ser vista en el uso que en varios medios de comunicación se hace del léxico. Así, las palabras que se utilizan en un determinado discurso retratarán o nombrarán de manera diferente, evocando una perspectiva concreta de análisis y entendimiento de la situación. $(1999,29)$.

11 En este punto parece conveniente reflexionar en torno a lo que Luce Irigaray, expone en su publicación Speculum of the other woman. (Irigaray, 1994) En este texto, la autora ahonda en la imposibilidad de la mujer de decir su realidad particular, al hallarse desde siempre constituida como una negación, forzada a usar un lenguaje que no le es propio. La autora se refiere a la mujer, a sus expresiones y a su deseo, como una existencia móvil, múltiple e inasible, que no responde a la lógica fijadora de lo masculino. En su multiplicidad, ellas han sido convertidas en objeto y se las ha definido sólo en términos de negación y falta, en relación a la existencia masculina. El lenguaje es un área hegemónica que, lejos de ofrecerles una posibilidad expresiva se constituye para ellas como la negación de ésta, quitándole la posibilidad de una 
manifestación fidedigna, que lograra contener su ser. Así, la posibilidad de observar y reflexionar en torno a los actos performativos que la obra presenta, como nuevas posibilidades de habla femenina, se erige como una invitación no podría pasar por alto.

12 Esta obra teatral logró sortear la censura por un período considerable y atrajo una importante audiencia durante el tiempo en que estuvo en exhibición. No todos los trabajos ni las compañías teatrales contaron con igual suerte. Los integrantes de la compañía teatral El Aleph, por ejemplo, tras montar Y al principio existía la vida... en 1974, fueron capturados por las fuerzas de represión del gobierno y llevados a campos de tortura. (Hurtado y Ochsenius, 1980, 24).

13 Nissim Sharim reconoce la importancia de los planteamientos de Brecht en el trabajo de ICTUS. Refiriéndose a esto, describe el concepto recién mencionado en el texto con las siguientes palabras: "La cuentas como un hecho lógico [una situación coloquial cualquiera] que no descubre nada de su horror, de su ridiculez. Entonces Brecht dice que hay que extrañar esto. Hay que separar de eso 'tan normal' aquellos elementos que no permiten ver el horror, el absurdo, el ridículo que subyace a esa situación." (Hurtado y Ochsenius, 1980, 82).

\section{Bibliografía}

Benjamin, Walter: La dialéctica del suspenso. Fragmentos sobre historia. Traducción, introducción y notas de Pablo Oyarzún Robles. Santiago-Chile: Ediciones LOM, 1995.

Benavente, David. "Ensayo 'Ave Felix' Teatro Chileno post-golpe". ICTUS, David Benavente, TIT: Pedro, Juan y Diego, Tres Marías y una Rosa, Santiago-Chile: Ediciones ChileAmérica CESOC, 1989.

Díaz, Jorge y Nissim Sharim, comp. ICTUS: la palabra compartida: antología. Santiago: Edebé; Editorial Don Bosco S.A., 2002.

Foucault, Michel: Conferencia "El orden del discurso", Lección inaugural en el Collège de France, pronunciada el 2 de diciembre de 1970. Barcelona, Tusquets Editores, 1992. Traducción de Alberto González Troyano. http://www.cholonautas.edu.pe/modulo/ upload/tallfouc.pdf (Revisado por última vez el 16 de diciembre, 2010).

Hurtado, María de la Luz y Mauricio Barría, comp. Antología: Un siglo de dramaturgia Chilena: 1910-2010, Tomo III. Santiago-Chile: Publicaciones Comisión Bicentenario Chile, 2010.

Hurtado, María de la Luz y Carlos Ochsenius. Teatro ICTUS. SantiagoChile: CENECA, 1980.

ICTUS, David Benavente, TIT. Pedro, Juan y Diego, Tres Marías y una Rosa, Santiago-Chile: Ediciones ChileAmérica CESOC, 1989.

Irigaray, Luce. Speculum of the other woman, [traducción de Guillian C. 
Gill], New York: Cornell University Press, 1994.

Chakravorty Spivak, Gayatri. “¿Puede hablar el subalterno?”, Revista Colombiana de Antropología, volumen 39, enero-diciembre, 2003, 297-364.

Rojo, Grinor. Muerte y resurrección del teatro chileno 1973-1983, Madrid: Ediciones Michay S.A., 1985.

Taylor, Diana. The Archive and the Repertoire: Performing Cultural Memory in the Americas. Durham and London: Duke University Press, 2003.

Van Dijk, Teun. "Conferencia: 'El análisis crítico del discurso'". Anthropos (Barcelona), 186 (septiembre-octubre, 1999): 23-36.

Van Dijk, Teun. Análisis del discurso ideológico [traducción de Ramón Alvarado], versión 6•UAM-X•México. 1996, 15-43.

Violi, Patrizia. El infinito singular. Madrid: Ediciones Cátedra, 1991. 